Journal of Research in Interprofessional

Practice and

Education

Vol. 4.2

November 2014

\title{
Curricular Factors that Unintentionally Affect Learning in a Community-Based Interprofessional Education Program: The Student Perspective
}

\author{
Shelley Doucet, PhD, RN; Diane MacKenzie, PhD, OT Reg (NS); \\ Elaine Loney, MSc; Anne Godden-Webster, MSc; Heidi Lauckner, PhD, \\ OT Reg (NS); Peggy Alexiadis Brown, MA; Cynthia Andrews, DDS; \\ \& Tanya L. Packer, PhD, OT Reg (NS)
}

\begin{abstract}
Background: The Dalhousie Health Mentors Program (DHMP) is a communitybased, pre-licensure interprofessional education initiative that aims to prepare health professional students for collaborative practice in the care of patients with chronic conditions. This program evaluation explores the students' 1) learning and plans to incorporate skills into future practice; 2 ) ratings of program content, delivery, and assignments; 3 ) perspectives of curricular factors that inadvertently acted as barriers to learning; and 4) program improvement suggestions.

Methods: All students $(N=745)$ from the 16 participating health programs were invited to complete an online mixed methods program evaluation survey at the conclusion of the 2012-2013 DHMP. A total of 295 students (40\% response rate) responded to the Likert-type questions analyzed using descriptive and non-parametric statistics. Of these students, 204 (69\%) provided responses to 10 openended questions, which were analyzed thematically.

Findings: While the majority of respondents agreed that they achieved the DHMP learning objectives, the mixed-methods approach identified curriculum integration, team composition, and effectiveness of learning assignments as factors that unintentionally acted as barriers to learning, with three key student recommendations for program improvement.

Conclusions: Educators and program planners need to be aware that even wellintended learning activities may result in unintended experiences that hamper interprofessional learning.

Keywords: Interprofessional education; Longitudinal; Health mentors program; Health professional student; Curriculum; Unintended; Barriers; Recommendations; Lessons learned
\end{abstract}

\section{Introduction}

Journal of Research in Interprofessional Practice and Education (JRIPE)

Vol. 4.2

(C) 2014

Corresponding author: Shelley Doucet. Email: sdoucet@unb.ca
Healthcare systems worldwide are undergoing tremendous reform to meet the increasingly complex healthcare needs of patients with chronic conditions. In Canada, all levels of government have adopted the Expanded Chronic Care Model [1] to guide policy reform. The model advocates for changes in both community and health systems in order to support a productive partnership between "informed activated patients" and "prepared and pro-active health care teams" in the delivery of care to people with chronic conditions [2]. Productive partnerships require a transformational change in professional roles, particularly in how professionals interact with people living with 
2

Interprofessional Education Program

Doucet, MacKenzie, Loney, GoddenWebster, Lauckner, Brown, Andrews, \& Packer

Journal of Research in Interprofessional Practice and Education

Vol. 4.2 November 2014 chronic conditions. These changes have been described as a transformation from the role of healthcare provider to healthcare collaborator [3]. Patients are a critical partner in these collaborative relationships, and their knowledge, skills, and confidence in the management of their own care, conceptualized as their "activation level" [4], are all factors that influence their health outcomes. In order to prepare health professional students for patient-centred practice, a current trend is the involvement of patients as educators [5]. Recent research has found that patients want to play an active role in health professional education, with the hope of making the healthcare system more collaborative and patient-centred [6].

In the Expanded Chronic Care Model, collaboration extends beyond the patientprovider relationship to include the entire healthcare team. To date, most health professionals practice in multidisciplinary teams, which often encourage them to work independently to achieve a common goal, rather than collaboratively. Healthcare teams need to shift away from practicing in silos to working proactively and collaboratively with each other and with patients to develop a shared plan of care [7]. This cultural change in practice is occurring with growing evidence that interprofessional collaboration (IPC) improves outcomes with patients (e.g., self-care knowledge), providers (e.g., work satisfaction), and the healthcare system (e.g., coordination of care) [8]. Meanwhile, the barriers to IPC are many, including multiple competing priorities, internal politics, miscommunication, lack of leadership that bridges disparate groups and fosters trust, and group dysfunction when team members are not participating collaboratively $[9,10]$.

As a result of the growing emphasis on interprofessional patient-centred practice, educating prepared and proactive teams has become a priority for entry to practice health professional education programs [11]. One way to prepare health professionals for collaborative practice is through pre-licensure interprofessional education (IPE) opportunities, which involve health professional students learning about, from, and with each other to improve health outcomes [12]. IPE activities can act as powerful tools for cultural change, causing learners and educators to challenge the existing patterns and paradigms within their current or future work environment by making them aware of team structure and the roles and responsibilities of various health professionals [10]. In addition, IPE activities provide an opportunity for students to participate in and critically examine team processes while practicing their skills at identifying and addressing problems and inefficiencies within a team setting. Through these activities, students are given the opportunity to cultivate a culture of collaboration rather than the traditional culture that involves individuals trying to solve problems in isolation [13].

There are a number of potential barriers associated with implementing IPE activities, including challenges associated with group dynamics, faculty support and training, and inflexible curricula [14]. Moreover, as in any teaching encounter, there are the planned or intended learning objectives and activities that are developed by educators; alongside these intended curricular objectives, students can also have unintended experiences or receive messages that are counter to the stated objectives [15]. These unintended experiences may be positive, creating an opportunity for a deeper 
3

Interprofessional Education Program

Doucet, MacKenzie, Loney, GoddenWebster, Lauckner, Brown, Andrews, \& Packer

Journal of Research in Interprofessional Practice and Education

Vol. 4.2 November 2014 learning experience, or negative, potentially contradicting the intended learning outcome(s). There is a gap in the IPE curriculum literature reporting students points of view with both the intended IPE learning experiences and the unintended experiences that create barriers to learning. Similar to research reporting on the effects of curriculum on professionalism development [16], students' interaction with the unintended curricular factors of IPE learning opportunities may also lead to an unwanted impact on their overall interprofessional learning and professional development. Accordingly, planners of interprofessional encounters that are either standalone events or within a broader curriculum need to consider the impact of the unintended and hidden factors on learning in order to make it more likely that students experience IPE initiatives as intended. Evaluation and improvement of these experiences needs to be responsive to constructive feedback from students. While some learners may experience very powerful and positive long-lasting effects of the unintended experiences (e.g., team members who worked together exceptionally well and elevated their skills beyond the expectations of the assignments), of more concern are those students who experience the effect of unintended but powerful negative experiences. The concern is that some students may not be able to appreciate the intentions of the IPE initiative, and that the negative encounter will impact future skill development, or worse, it may create a self-perpetuating culture of negative comments or "recreational complaining" [17] about team members, professions represented, and/or IPE in general.

\section{Context}

The Dalhousie Health Mentors Program (DHMP) is one example of an IPE initiative that aims to prepare health professional students for collaborative practice in the care of patients with chronic conditions [18]. The objectives of the DHMP are to increase students' knowledge of 1) chronic conditions and/or disabilities, 2) patient/client-centredness, 3) team functioning, and 4) interprofessional communication. The DHMP was piloted in 2010, building upon the Thomas Jefferson University Health Mentors Program [19].

The unique feature of this innovative program is the participation of volunteer "health mentors." Health mentors are community volunteers with a chronic condition and/or disability who, over an eight-month period, are willing to share with a small interprofessional team of four students their experience of living with their condition and navigating the healthcare system. One health mentor is assigned to each student team. Throughout their interactions with the mentors, student teams do not provide care, treatment, or advice; rather, they listen to and learn from the health mentors, who share their distinct perspective. The DHMP program was designed for learners in the first year of their professional program of study, hence the program objectives did not endorse or allow intervention by student teams. However, students from five of the 16 programs were in the second or third year of their professional program. The team composition was purposefully planned to randomly include students from 3 to 4 different programs. Team composition was not tied to the mentor's chronic condition(s) to facilitate the team's focus on learning about team functioning and the 
4

Interprofessional Education Program

Doucet, MacKenzie, Loney, GoddenWebster, Lauckner, Brown, Andrews, \& Packer

Journal of Research in Interprofessional Practice and Education

Vol. 4.2 November 2014 client/patient as a person first. The mentor may or may not have any experience working with the professions represented on their student team.

In the 2012-2013 academic year, students from 16 professional programs at three institutions participated in the DHMP, which involved three health mentor visits in the community and three meetings with a faculty supervisor who monitored the learning and assignments. Students were required to complete team and individual assignments. The ten team assignments were: 1) the team plan and the mentor's story, 2) three team reflective exercises, which were designed to guide the teams' selfassessment of their teamwork and were completed after meeting with the faculty supervisor, and 3) five team participation forms that reported on each team member's contributions to the team's assignments and mentor visits. The two individual assignments involved: 1) a peer assessment, which was confidential and submitted to the supervisor, and 2) a final written reflection. Student teams were supervised and evaluated by a faculty member from one of the participating professional programs, regardless of team member composition. Student participation in the DHMP experience was assessed on a pass/fail basis and was a requirement for graduation in most programs. The DHMP was not intended to be an add-on to curricula; rather, it was to be connected with the curriculum in each of the participating programs. For example, some programs included the DHMP as an interprofessional learning experience within an existing course, and some programs allocated a small percentage of the final course mark to successful participation in the DHMP (e.g., 5-10\%). The majority of the participating programs shared a common time that is protected for IPE activities, such as the DHMP supervisor and mentor meetings.

The Expanded Chronic Care Model [1] is used as a guiding framework for the DHMP, whereby the health mentors represent informed activated patients and the students represent developing pro-active healthcare teams. The Canadian Interprofessional Health Collaborative (CIHC) National Competency Framework [20] is used to frame the DHMP interprofessional collaboration objectives. Specifically, three CIHC competencies were the intended focus of this program: interprofessional communication, team functioning, and patient/client-centred care. The team and individual assignments were designed to incorporate active learning strategies that required the students to reflect on their experiences with their team and mentor and, either individually or collectively, present information in a way that illustrated their new and deep learning. These strategies are known to improve student outcomes in such skills as critical thinking, communication, and problem solving $[21,22,13]$. The DHMP adopts a learner-centred approach by placing the responsibility for learning on the student and encouraging further development of a "deep approach to learning," which can lay the foundation for lifelong learning $[23,24]$.

\section{Purpose}

The purpose of this article is to share program evaluation results that explored the students'1) learning in the DHMP and what they planned to incorporate into their future practice; 2) ratings of the program content, delivery, and assignments; 3 ) perspectives of the intended and unintended curricular factors that acted as barri- 
5

Interprofessional Education Program

Doucet, MacKenzie, Loney, GoddenWebster, Lauckner, Brown, Andrews, \& Packer
Journal of Research in Interprofessional Practice and Education

Vol. 4.2 November 2014 ers to their learning; and 4) suggestions for program improvement. From these results, this article recommends strategies for improving the DHMP and highlights key lessons learned on how to strengthen the delivery of similar IPE initiatives such that the unintended barriers to learning do not undermine the intended learning outcomes.

\section{Methods}

A retrospective program evaluation survey was designed to gather the students' experiences during the eight-month DHMP. The evaluation survey is administered to students participating in the DHMP at the conclusion of the program each year. Survey questions inquire about the students' perspectives on the learning objectives, orientation activities, teamwork, health mentor involvement, the team supervisor's role, integration into the students' program, range of assignments, and the most important lessons they learned from the program. This article reports on the data from the 2012-2013 academic year. The evaluation was designed as a concurrent triangulation survey [25]. The Research Ethics Board (REB) at Dalhousie University confirmed that the DHMP evaluation survey met the federal and institutional exemption criteria and as such did not require REB approval for publication.

\section{Participants}

The DHMP students were from three Canadian academic institutions across two provinces: 14 of the 16 programs are affiliated with Dalhousie University, Nova Scotia (NS), and the remaining students are from the Dalhousie Faculty of Medicine distributed learning site, University of New Brunswick, and the New Brunswick Community College in New Brunswick (NB). All students $(N=745)$ enrolled in the DHMP during the 2012-2013 academic year were invited to participate in the online program evaluation survey. There were 346 students who opened the survey (but did not persist past question 1) and 295 students ( $40 \%$ response rate) who completed the online survey.

\section{Data collection}

The program evaluation survey questions examined in this article explored the students' views on the DHMP learning objectives, content, delivery, and assignments. The online survey was developed using Opinio Survey software (Opinio 6.4.1, Copyright 1998-2011 Object Planet) and hosted on the Dalhousie University server. Data were collected using a mixture of Likert-type questions (5-point measurement of agreement and disagreement scale) and open-ended questions that solicited students' comments on their overall learning experience. Questions were formatted using Opinio Survey software (Opinio 6.4.1, Copyright 1998-2011 Object Planet) and the survey was hosted on the University's server. All responses to open-ended questions, referred to as free-text comments, were analyzed regardless of the link to survey items.

\section{Analysis}

The evaluation data were exported from Opinio into Microsoft Excel 2011 (Microsoft, Redmond, WA), cleaned, and then divided into quantitative and qualita- 
6

Interprofessional Education Program

Doucet, MacKenzie, Loney, GoddenWebster, Lauckner, Brown, Andrews, \& Packer
Journal of Research in Interprofessional Practice and Education

Vol. 4.2 November 2014 tive datasets, each initially analyzed independently from the other. Quantitative data were imported into Stata (Version12.0, Stata Corporation) for descriptive analysis; qualitative data were imported into NVivo 10 (QSR International Pty Ltd, Victoria, Australia) for analysis.

Proportions of respondents who "strongly disagreed," "disagreed," "agreed," "strongly agreed," or answered "neither" to the Likert-type questions regarding DHMP learning objectives, content, delivery, and assignments were calculated. The Likert-type ratings for the respondents who provided free-text comments were compared to those who chose not to provide comments using nonparametic WilcoxinMann-Whitney tests. These tests were conducted to examine whether those who chose to provide comments were reflective of the overall survey respondents.

Thematic analysis [26,27] and content analysis [28] were used to analyze the students' voluntary written comments contained in 10 free-text survey fields imported into NVivo [29]. The initial coding structure was developed by one research team member who had no association with the DHMP prior to the analysis phase. Codes were derived by open coding responses as they appeared for each survey question and by using a priori topics presented by the survey. The coding structure was reviewed by one of the principal investigators, who was very familiar with the data and the DHMP, to assess the structure's comprehensiveness and accuracy in representing the data. The inductive process of open coding continued using NVivo 10 for data management, with each individual's responses examined for meaning and considered in the context of each respondent's comments in their entirety. Coding was conducted without regard to a comment's placement in a specific survey field. For example, students often provided information on what they learned and would apply in future interactions with patients in more than one comment box; all of these comments were open coded for meaning and grouped with educational benefits and/or other relevant categories. A constant comparative approach was used to refine coding and category development, group categories, and to detect patterns and relationships among categories. Themes and subthemes were identified and interpreted in consultation with a second team member who also reviewed the findings for accuracy and completeness. Quantitative and qualitative findings were then compared for consistencies between ratings and textual comments.

\section{Results}

A total of 295 students responded to the online program evaluation survey, representing a 40\% response rate of the 2012-2013 DHMP student population. Of the 295 respondents, 204 (69\%, or $27 \%$ of all students) provided at least one free-text comment. Table 1 provides information on the proportion of respondents who provided comments and their program demographic characteristics. The findings are organized as follows: 1) student learning as participants in the DHMP; 2) students' survey ratings about the DHMP content, delivery, and assignments; 3 ) intended and unintended learning experiences; and 4) students' recommendations and suggestions for program improvement. 
7

Interprofessional Education Program

Doucet, MacKenzie, Loney, GoddenWebster, Lauckner, Brown, Andrews, \& Packer
Journal of Research in Interprofessional Practice and Education

Vol. 4.2

November 2014
Table 1

\section{Student demographic information and response} rate by professional program

\begin{tabular}{|l|c|c|c|c|c|}
\hline \multicolumn{1}{|c|}{ Professional program } & $\begin{array}{c}\text { Year in } \\
\text { program/ } \\
\text { length of } \\
\text { program }\end{array}$ & $\begin{array}{c}\text { Direct entry } \\
\text { from high } \\
\text { school }\end{array}$ & $\begin{array}{c}\text { Postgraduate } \\
\text { program }\end{array}$ & $\begin{array}{c}\text { No. survey } \\
\text { respondents } \\
\text { with } \\
\text { comments }\end{array}$ & $\begin{array}{c}\text { Percent of } \\
\text { program } \\
\text { respondents } \\
\text { providing } \\
\text { comments }\end{array}$ \\
\hline Audiology & $2 / 2$ & N & Y & 5 & $83 \%$ \\
\hline Clinical Psychology & $1 / 5$ & N & PhD & 3 & $60 \%$ \\
\hline Clinical Vision Science & $1 / 2$ & $\mathrm{~N}$ & $\mathrm{Y}$ & 0 & $<1 \%$ \\
\hline Dentistry & $1 / 4$ & $\mathrm{~N}$ & $\mathrm{DDS}$ & 9 & $39 \%$ \\
\hline Health Administration & $1 / 2$ & $\mathrm{~N}$ & $\mathrm{Y}$ & 6 & $75 \%$ \\
\hline Medicine (Dalhousie, NS) & $1 / 4$ & $\mathrm{~N}$ & $\mathrm{MD}$ & 42 & $77 \%$ \\
\hline Medicine (Dalhousie, NB) & $1 / 4$ & $\mathrm{~N}$ & $\mathrm{MD}$ & 11 & $79 \%$ \\
\hline Nuclear Medicine Technology & $1 / 4$ & $\mathrm{Y}$ & $\mathrm{N}$ & 1 & $50 \%$ \\
\hline Nursing (Dalhousie) & $3 / 4$ & $\mathrm{Y}$ & $\mathrm{N}$ & 29 & $63 \%$ \\
\hline Nursing (UNB) & $1 / 4$ & $\mathrm{Y}$ & $\mathrm{N}$ & 11 & $63 \%$ \\
\hline Occupational Therapy & $1 / 2$ & $\mathrm{~N}$ & $\mathrm{Y}$ & 12 & $75 \%$ \\
\hline Pharmacy & $1 / 4$ & $\mathrm{~N}$ & $\mathrm{~N}$ & 23 & $64 \%$ \\
\hline Physiotherapy & $1 / 2$ & $\mathrm{~N}$ & $\mathrm{Y}$ & 16 & $80 \%$ \\
\hline Radiological Technology & $3 / 4$ & $\mathrm{Y}$ & $\mathrm{N}$ & 2 & $100 \%$ \\
\hline Respiratory Therapy & $3 / 4$ & $\mathrm{Y}$ & $\mathrm{N}$ & 4 & $57 \%$ \\
\hline Social Work & $1 / 4$ & $\mathrm{~N}$ & $\mathrm{~N}$ & 17 & $74 \%$ \\
\hline Speech- Language Pathology & $2 / 2$ & $\mathrm{~N}$ & $\mathrm{Y}$ & 12 & $92 \%$ \\
\hline No Profession stated & & & & 1 & $100 \%$ \\
\hline & & & TOTAL & $\mathbf{2 0 4}$ & $\mathbf{6 9 \%}$ \\
\hline
\end{tabular}

\section{Student learning as participants in the DHMP}

Table 2 provides the group respondent rankings for the four DHMP learning objectives. Collapsing the two ratings "agree" and "strongly agree," it can be seen that the majority of respondents felt they met all of the learning objectives: $76 \%$ met the patient/client-centred objective, $73 \%$ met the objective related to chronic conditions, $70 \%$ met the team functioning objective, and $64 \%$ met the interprofessional communication objective. A Wilcoxin-Mann-Whitney nonparametric test did not find any significant differences between the rankings of the group who provided comments and the group who did not, for any of the four DHMP learning objective questions ( $p$-value $<.05)$.

Overall, 164 students (56\% of all survey respondents, $80 \%$ of those providing freetext comments) commented on having gained education benefits as a participant in the DHMP. Of these, 128 described what they attained and what they would incorpo- 
8

Interprofessional Education Program

Doucet, MacKenzie, Loney, GoddenWebster, Lauckner, Brown, Andrews, \& Packer
Journal of Research in Interprofessional Practice and Education

Vol. 4.2

November 2014
Table 2

\section{Student rankings of learning objectives}

\begin{tabular}{|l|c|c|c|c|c|c|}
\hline & & $\begin{array}{c}\text { Strongly } \\
\text { disagree }\end{array}$ & Disagree & Neither & Agree & $\begin{array}{c}\text { Strongly } \\
\text { agree }\end{array}$ \\
\hline Learning objectives & $\mathbf{N}$ & $\mathbf{1}$ & $\mathbf{2}$ & $\mathbf{3}$ & $\mathbf{4}$ & $\mathbf{5}$ \\
\hline $\begin{array}{c}\text { 1. I achieved the learning objectives } \\
\text { related to chronic conditions. }\end{array}$ & 294 & $\begin{array}{c}8 \\
(2.7 \%)\end{array}$ & $\begin{array}{c}22 \\
(7.5 \%)\end{array}$ & $\begin{array}{c}51 \\
(17.4 \%)\end{array}$ & $\begin{array}{c}124 \\
(42.2 \%)\end{array}$ & $\begin{array}{c}89 \\
(30.3 \%)\end{array}$ \\
\hline $\begin{array}{c}\text { 2. I achieved the learning objectives } \\
\text { related to IP communication. }\end{array}$ & 295 & $\begin{array}{c}15 \\
(5.1 \%)\end{array}$ & $\begin{array}{c}33 \\
(11.2 \%)\end{array}$ & $\begin{array}{c}57 \\
(19.3 \%)\end{array}$ & $\begin{array}{c}117 \\
(39.7 \%)\end{array}$ & $\begin{array}{c}73 \\
(24.8 \%)\end{array}$ \\
\hline $\begin{array}{c}\text { 3. I achieved the learning objectives } \\
\text { related to client-centeredness. }\end{array}$ & 294 & $\begin{array}{c}7 \\
(2.4 \%)\end{array}$ & $\begin{array}{c}11 \\
(3.7 \%)\end{array}$ & $\begin{array}{c}53 \\
(18.0 \%)\end{array}$ & $\begin{array}{c}115 \\
(39.1 \%)\end{array}$ & $\begin{array}{c}108 \\
(36.7 \%)\end{array}$ \\
\hline $\begin{array}{c}\text { 4. I achieved the learning objectives } \\
\text { related to team functioning. }\end{array}$ & 295 & $\begin{array}{c}11 \\
(3.7 \%)\end{array}$ & $\begin{array}{c}20 \\
(6.78 \%)\end{array}$ & $\begin{array}{c}58 \\
(19.7 \%)\end{array}$ & $\begin{array}{c}120 \\
(40.7 \%)\end{array}$ & $\begin{array}{c}86 \\
(29.2 \%)\end{array}$ \\
\hline
\end{tabular}

rate into future interactions with patients/clients and/or other health professionals. Within the education benefits, three subthemes predominated the qualitative data: 1) patient-centredness, 2) interprofessional skills, and 3) collaborative attitudes. These three subthemes were overlapping and interrelated, each contributing to the development of what can be conceptualized as authentic, patient-centred collaborations, which captures the collective experiences of students' perceived learning in the program. Figure 1 depicts how these three subthemes have been conceptualized and their key features.

Figure 1

\section{Educational benefits: Developing authentic, patient-centred collaboration}

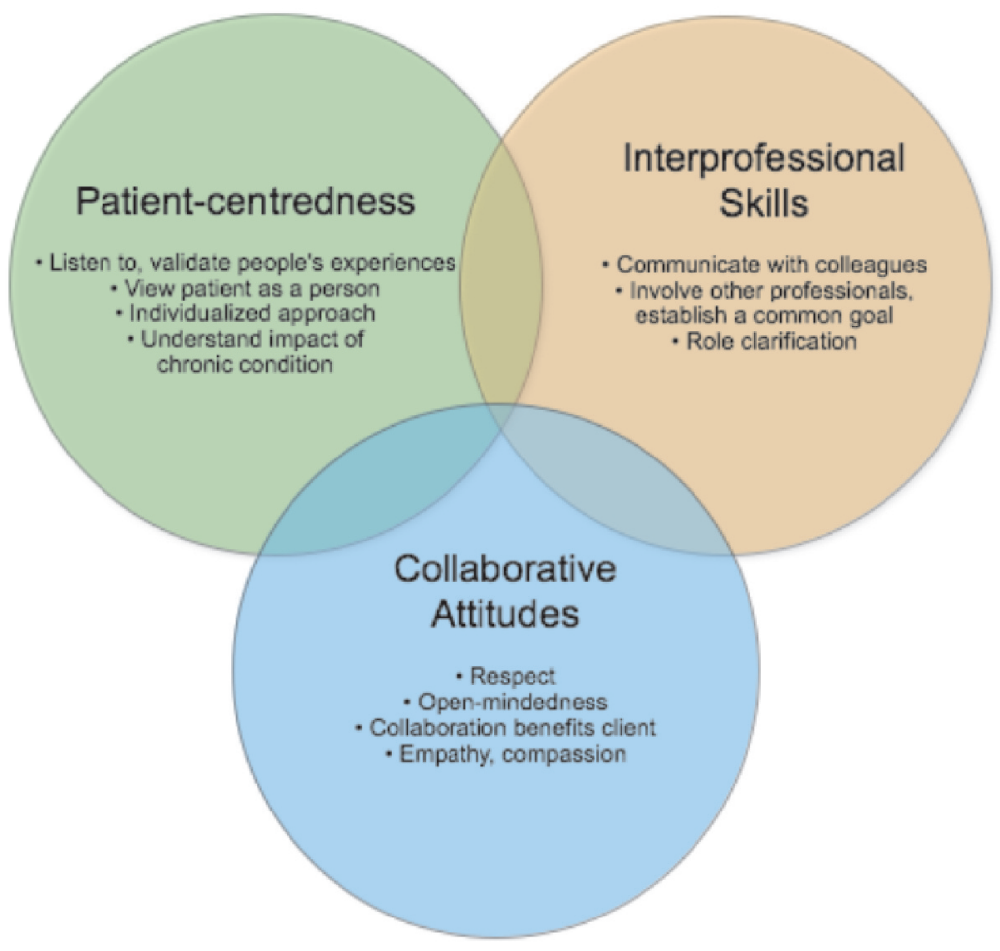




\section{JRIPE}

9

Interprofessional Education Program

Doucet, MacKenzie, Loney, GoddenWebster, Lauckner, Brown, Andrews, \& Packer

Table 3 provides exemplary quotes of the subthemes. In contrast, the key theme for a very small proportion of students was limited educational value added, described by 36 students from nine programs (12\% of all survey respondents, $17 \%$ of those providing free-text comments). This viewpoint appeared to be linked to a negative assessment of the program's time demands relative to perceived educational gain, and/or perceptions that they already had the requisite knowledge or skills to meet the objectives.

\section{Table 3}

\section{Main educational benefit subthemes: Exemplary quotes}

\begin{abstract}
1. Patient-centredness
I think the most valuable thing I took away from the program was to always put patients first. (Dentistry student)

Listen to the service user. (Social Work student)

Always trying to keep in mind that the client knows their story the best and is the only person who can continue to write their own story. I work in collaboration with my clients to determine goals and objectives, gather information, work on interventions, and provide support and services, but they will decide how to use that support and those services in the end. (Occupational Therapy student)

I really liked meeting and interacting with our health mentor. I'll be more conscious of the fact that each person's story is different. What they value is different, as is how they are affected by their illness. Exploring what is important to our patients as they deal with their illness is important to helping them recover and achieve a better quality of life. (Medical student)
\end{abstract}

\section{Interprofessional skills}

I will remember that I am a valuable member of interprofessional teams. Previously, I had thought that I had to obey the hierarchy inherent in healthcare teams, but I see now that teams work best when everyone feels like they are on the same level. This will encourage me to be a more active participant on teams in the healthcare setting. (Nursing student)

I will be very open and aware to the experiences and resources that each profession and individual I will work with might bring forth. (Social Work student)

I will attempt to make sure that other health professionals fully understand my point of view and that I understand theirs in turn. I will try to come to the same conclusion on decisions that will benefit the patient overall. (Pharmacy student)

\section{Collaborative attitudes}

Understanding that the patients live with the condition, so they know what works and does not work for them. (Nursing student)

No one is better than the other; we all have our expertise - put that to practice by respecting others. (Medical student)

It is important to respect and be open to the opinions and ideas of others in order to develop the best treatment approach. (Physiotherapy student)

I think we have to realize that each of the professions has something to bring to the table and if we collaborate it will be beneficial for the patient and us. (Pharmacy student)

Listen to what other professions have to say and genuinely make an effort to incorporate their suggestions into practice. Don't assume my profession is superior. (Nursing student) 
JRIPE

10

Interprofessional Education Program

Doucet, MacKenzie, Loney, GoddenWebster, Lauckner, Brown, Andrews, \& Packer
Students' survey ratings about the DHMP content, delivery, and assignments Table 4 provides the proportion of respondents who "strongly disagreed," "disagreed," "agreed," "strongly agreed," or answered "neither" to questions regarding DHMP content and delivery. With the exception of the survey question that inquired about the level of agreement with the students' knowledge of other students' professions $(p<$ $.05)$, the Wilcoxin-Mann-Whitney nonparametric test found no significant differences between the ratings of the respondents who provided comments and those who did not on the questions analyzed regarding DHMP content, delivery, and assignments. Given this minimal difference with all the questions considered, aggregated ratings (those providing and not providing free text) are reported, with the two groups considered similar to each other.

Table 4

\section{Student ratings of program content and delivery}

\begin{tabular}{|l|c|c|c|c|c|c|}
\hline & & $\begin{array}{c}\text { Strongly } \\
\text { disagree }\end{array}$ & Disagree & Neither & Agree & $\begin{array}{c}\text { Strongly } \\
\text { agree }\end{array}$ \\
\hline \multicolumn{1}{|c|}{ Program content and delivery } & $\mathbf{N}$ & $\begin{array}{c}\mathbf{1} \\
\#(\%)\end{array}$ & $\begin{array}{c}\mathbf{2} \\
\#(\%)\end{array}$ & $\begin{array}{c}\mathbf{3} \\
\#(\%)\end{array}$ & $\begin{array}{c}4 \\
\#(\%)\end{array}$ & $\begin{array}{c}\mathbf{5} \\
\#(\%)\end{array}$ \\
\hline $\begin{array}{l}\text { My team was able to schedule visits with our } \\
\text { mentor so that all members could attend. }\end{array}$ & 280 & $\begin{array}{c}4 \\
(1.4)\end{array}$ & $\begin{array}{c}23 \\
(8.2)\end{array}$ & $\begin{array}{c}35 \\
(12.5)\end{array}$ & $\begin{array}{c}89 \\
(31.8)\end{array}$ & $\begin{array}{c}129 \\
(46.1)\end{array}$ \\
\hline $\begin{array}{l}\text { Other students on my team made valuable } \\
\text { contributions to my learning. }\end{array}$ & 280 & $\begin{array}{c}5 \\
(1.8)\end{array}$ & $\begin{array}{c}25 \\
(8.9)\end{array}$ & $\begin{array}{c}58 \\
(20.7)\end{array}$ & $\begin{array}{c}96 \\
(34.3)\end{array}$ & $\begin{array}{c}96 \\
(34.3)\end{array}$ \\
\hline $\begin{array}{l}\text { It makes sense to me that my program is involved } \\
\text { in the Health Mentors Program. }\end{array}$ & 282 & $\begin{array}{c}19 \\
(6.7)\end{array}$ & $\begin{array}{c}28 \\
(9.9)\end{array}$ & $\begin{array}{c}57 \\
(20.2)\end{array}$ & $\begin{array}{c}88 \\
(31.2)\end{array}$ & $\begin{array}{c}90 \\
(31.9)\end{array}$ \\
\hline $\begin{array}{l}\text { The number of mentor visits (three) was } \\
\text { appropriate. }\end{array}$ & 275 & $\begin{array}{c}20 \\
(7.3)\end{array}$ & $\begin{array}{c}44 \\
(16.0)\end{array}$ & $\begin{array}{c}41 \\
(14.9)\end{array}$ & $\begin{array}{c}74 \\
(26.9)\end{array}$ & $\begin{array}{c}96 \\
(34.9)\end{array}$ \\
\hline $\begin{array}{l}\text { Inow know more about the professions of the } \\
\text { other students on my team. }\end{array}$ & $279 *$ & $\begin{array}{c}28 \\
(10.0)\end{array}$ & $\begin{array}{c}32 \\
(11.5)\end{array}$ & $\begin{array}{c}54 \\
(19.4)\end{array}$ & $\begin{array}{c}95 \\
(34.1)\end{array}$ & $\begin{array}{c}70 \\
(25.1)\end{array}$ \\
\hline $\begin{array}{l}\text { The timing of the mentor visits (Visits 1 and } 2 \text { in } \\
\text { Fall term; Visit } 3 \text { in Winter term) was appropriate. }\end{array}$ & 273 & $\begin{array}{c}29 \\
(10.6)\end{array}$ & $\begin{array}{c}28 \\
(10.3)\end{array}$ & $\begin{array}{c}57 \\
(20.9)\end{array}$ & $\begin{array}{c}97 \\
(35.5)\end{array}$ & $\begin{array}{c}62 \\
(22.7)\end{array}$ \\
\hline $\begin{array}{l}\text { The Health Mentors Program is in the appropriate } \\
\text { year of my program. }\end{array}$ & 282 & $\begin{array}{c}42 \\
(14.9)\end{array}$ & $\begin{array}{c}31 \\
(11.0)\end{array}$ & $\begin{array}{c}46 \\
(16.3)\end{array}$ & $\begin{array}{c}87 \\
(30.1)\end{array}$ & $\begin{array}{c}76 \\
(27.0)\end{array}$ \\
\hline $\begin{array}{l}\text { Team meetings in person with the supervisor were } \\
\text { helpful. }\end{array}$ & 273 & $\begin{array}{c}33 \\
(12.1)\end{array}$ & $\begin{array}{c}46 \\
(16.9)\end{array}$ & $\begin{array}{c}70 \\
(25.6)\end{array}$ & $\begin{array}{c}66 \\
(24.2)\end{array}$ & $\begin{array}{c}58 \\
(21.3)\end{array}$ \\
\hline $\begin{array}{l}\text { The Health Mentors Program is well integrated } \\
\text { into my program. }\end{array}$ & 280 & $\begin{array}{c}59 \\
(21.1)\end{array}$ & $\begin{array}{c}60 \\
(21.4)\end{array}$ & $\begin{array}{c}86 \\
(30.7)\end{array}$ & $\begin{array}{c}47 \\
(16.8)\end{array}$ & $\begin{array}{c}28 \\
(10.0)\end{array}$ \\
\hline
\end{tabular}

* Significant difference $(p<.05)$ between respondents with comments and respondents without comments

After collapsing the response categories "agree" and "strongly agree," more than half of the respondents were in agreement that: 1) the team was able to schedule joint mentor/team visits (77.9\%); 2) other students made valuable learning contributions to the respondent's learning $(68.6 \%) ; 3)$ it made sense for the respondent's program to be involved with DHMP $(63.1 \%) ; 4)$ the number of mentor visits was appropriate $(61.8 \%)$; 5) respondents learned more about their team members' professions
Vol. 4.2
November 2014

ournal of Research in Practice and Education 
JRIPE

11

Interprofessional Education Program

Doucet, MacKenzie, Loney, GoddenWebster, Lauckner, Brown, Andrews, \& Packer
$(59.2 \%)$; 6) the timing of the mentor visits was appropriate $(58.2 \%)$; and 7) the DHMP was in the appropriate year of their respective program (57.1\%). Less than half of the respondents (45.5\%) agreed that the team meetings in person with their supervisor were helpful, and only one third of respondents (26.8\%) agreed that the DHMP was well integrated into their respective programs.

In addition to the DHMP content and delivery questions, similar analysis was completed on the questions related to the assignments. Table 5 provides respondent ratings on the six questions related to the DHMP assignments. After collapsing "strongly agree" and "agree" responses, on only one assignment (the Health Mentor's Story) did the majority of respondents (50.6\%) agree that it was an effective learning experience. The individual peer assessment received the next highest rating of agreement (44.2\%), and the final self-reflection received an agreement rating of $38.7 \%$. The least favourably rated assignment was the team reflective exercise designed to monitor team function-

Table 5

\section{Student ratings of assignment components}

\begin{tabular}{|c|c|c|c|c|c|c|}
\hline & & $\begin{array}{l}\text { Strongly } \\
\text { disagree }\end{array}$ & Disagree & Neither & Agree & $\begin{array}{c}\text { Strongly } \\
\text { agree }\end{array}$ \\
\hline Assignment components & $N$ & $\begin{array}{c}1 \\
\#(\%)\end{array}$ & $\begin{array}{c}2 \\
\#(\%)\end{array}$ & $\begin{array}{c}3 \\
\#(\%)\end{array}$ & $\begin{array}{c}4 \\
\#(\%)\end{array}$ & $\begin{array}{c}5 \\
\#(\%)\end{array}$ \\
\hline $\begin{array}{l}\text { The Our Health Mentor's Story assignment (done } \\
\text { by the whole team and submitted in January) } \\
\text { provided an effective learning experience. }\end{array}$ & 273 & $\begin{array}{c}30 \\
(11.0)\end{array}$ & $\begin{array}{c}27 \\
(9.9)\end{array}$ & $\begin{array}{c}78 \\
(28.6)\end{array}$ & $\begin{array}{c}92 \\
(33.7)\end{array}$ & $\begin{array}{c}46 \\
(16.9)\end{array}$ \\
\hline $\begin{array}{l}\text { The individual Peer Assessment assignment } \\
\text { (where I individually assessed each team member, } \\
\text { submitted in January) was helpful for } \\
\text { communicating team strengths and limitations to } \\
\text { my supervisor. }\end{array}$ & 274 & $\begin{array}{c}40 \\
(14.6)\end{array}$ & $\begin{array}{c}37 \\
(13.5)\end{array}$ & $\begin{array}{c}76 \\
(27.7)\end{array}$ & $\begin{array}{c}86 \\
(31.4)\end{array}$ & $\begin{array}{c}35 \\
(12.8)\end{array}$ \\
\hline $\begin{array}{l}\text { The final Self-Reflection assignment (individual, } \\
\text { about me and what I experienced and learned in } \\
\text { the Health Mentors Program, submitted in March) } \\
\text { deepened my learning. }\end{array}$ & 274 & $\begin{array}{c}52 \\
(19.0)\end{array}$ & $\begin{array}{c}42 \\
(15.3)\end{array}$ & $\begin{array}{c}74 \\
(27.0)\end{array}$ & $\begin{array}{c}76 \\
(27.7)\end{array}$ & $\begin{array}{c}30 \\
(11.0)\end{array}$ \\
\hline $\begin{array}{l}\text { The Team Participation Reports (completed after } \\
\text { each mentor visit and each team assignment) } \\
\text { were an effective way to record the contributions } \\
\text { of each team member to mentor visits and the } \\
\text { completion of assignments. }\end{array}$ & 273 & $\begin{array}{c}65 \\
(23.8)\end{array}$ & $\begin{array}{c}40 \\
(14.7)\end{array}$ & $\begin{array}{c}77 \\
(28.2)\end{array}$ & $\begin{array}{c}62 \\
(22.7)\end{array}$ & $\begin{array}{c}29 \\
(10.6)\end{array}$ \\
\hline $\begin{array}{l}\text { The Team Plan assignment (done by the whole } \\
\text { team, started at orientation and submitted in } \\
\text { October) provided an effective learning experience. }\end{array}$ & 273 & $\begin{array}{c}48 \\
(17.6)\end{array}$ & $\begin{array}{c}58 \\
(21.3)\end{array}$ & $\begin{array}{c}80 \\
(29.3)\end{array}$ & $\begin{array}{c}64 \\
(23.4)\end{array}$ & $\begin{array}{c}23 \\
(8.4)\end{array}$ \\
\hline $\begin{array}{l}\text { The Team Reflective Exercises (completed by all } \\
\text { team members at the end of each team cluster } \\
\text { meeting) were an effective way to monitor our } \\
\text { team functioning. }\end{array}$ & 273 & $\begin{array}{c}66 \\
(24.2)\end{array}$ & $\begin{array}{c}58 \\
(21.3)\end{array}$ & $\begin{array}{c}66 \\
(24.2)\end{array}$ & $\begin{array}{c}58 \\
(21.3)\end{array}$ & $\begin{array}{c}25 \\
(9.2)\end{array}$ \\
\hline
\end{tabular}

Journal of Research in Interprofessional Practice and Education

Vol. 4.2

November 2014 


\section{JRIPE}

12

Interprofessional Education Program

Doucet, MacKenzie, Loney, GoddenWebster, Lauckner, Brown, Andrews, \& Packer
Journal of Research in Interprofessional Practice and Education

Vol. 4.2

November 2014
Journal of Research in Interprofessional Practice and Education

ing, which received only a $30.5 \%$ agreement rating. Of the remaining assignment questions, $33.3 \%$ of respondents agreed that the team participation reports were an effective way to record contributions of each team member, and $31.8 \%$ agreed that the team plan assignment provided an effective learning experience.

\section{Intended and unintended learning experiences}

In general, the students reported agreement ratings for the majority of the intended DHMP content and delivery. However, the quantitative ratings reported in the text above and in Tables 4 and 5, taken together with the students' qualitative responses, identified three areas of concern with the curriculum as experienced by the students, which acted as barriers to the intended DHMP learning outcomes: 1) curriculum

\section{Table 6}

\section{Examples of unintended curriculum learning experiences: Exemplary quotes}

\section{Curriculum integration}

There could be more discussion around the program with the content of the [home] program.

It was difficult to schedule meetings with my group. All of our meetings had to take place on the weekend. My program ... did not have the time blocked off for health mentors like others did. It would have been helpful and it would have been nice to have other meeting times other than the weekend.

Meetings hard to schedule especially during final exam study time and with other professions as their schedules are different.

Although I agree that it makes sense to me that my program is involved in the Health Mentors program, it required a lot of work that did not count for any points towards our classes.

Although the Health Mentors Program was a great experience, given the time commitment required it seems that clinical programs gain more than my program

\section{Team composition factors}

I realize the nursing program does this in their third year and I am not aware of any others who do it any other year besides first. I think first year is too early because we do not have strong views from our fields and there is a lot of agreeing - while this is good, it limits our learning from one another.

I am also not convinced that pairing 1 st year ... students [who have a previous degree] with 1 st year students from other programs (some of whom are 17 years old and have minimal exposure to their given disciplines) is the best way to learn about other disciplines.

This program seems to be a better fit [earlier in programs] as all group members would have equal novice understanding of the conditions. In this program, [there was] much reliance on [third year] students to figure out meeting times and to explain concepts. Very little contribution by other team mates on the basis of not having education on chronic conditions.

I will never be working with the professionals I was paired with. It would make more sense for me to be paired with doctors or health administrators. I would have liked to [have] had the chance to network with these professionals since they are the ones I will rely on in my profession.

My health mentor was never involved with my profession, so I feel I did not get as much out of the program as I could have. 
Interprofessional Education Program

Doucet, MacKenzie, Loney, GoddenWebster, Lauckner, Brown, Andrews, \& Packer
Journal of Research in Interprofessional Practice and Education

Vol. 4.2 November 2014

\section{Interprofessional learning activities}

This just felt like another group project with fellow classmates. I did not learn anything about the professions of my teammates because there was no real way to incorporate our individual roles.

In the ... program we are continually situated in team/group settings. Except for the fact that I had outstanding team members and achieved the learning objectives, I believe I could have attained this with my own peers.

I found the program too assignment-based, and less based on trying to accomplish objectives. If less emphasis was put on completing assignments and more on actually meeting as teams and discussing things, said objectives would be met much more by students.

The value of the program is in the discussions with the mentor. These additional assignments did not contribute anything to my learning and seemed to merely be busy work to provide material for evaluation.

To me the team reflective exercises and team participation reports were not useful for providing honest feedback. Of course there were members of the team who did not pull their own weight, but when they are sitting next to you while you write these up, how are you supposed to say "so-and-so did not pull their own weight?" It's not realistic. So everyone was the same; "everyone participated, we worked well together, we are a good team."

The cluster meetings were not very necessary. Something needs to be added to them to make them more productive and beneficial.

integration into student programs, 2) team composition, and 3) effectiveness of the interprofessional learning activities. Table 6 displays exemplary quotes of the students' reflections on the unintended curriculum learning experiences.

\section{Curriculum integration}

Many students expressed the view that the DHMP was not well integrated into their overall professional curriculum experience, despite the fact that the DHMP is not supposed to be an add-on to a curriculum; rather, it is to be connected with the curriculum in each of the participating health professional programs. Lack of curriculum integration was manifested in three main areas: integration of profession-specific and interprofessional learning, scheduling conflicts, and issues of academic credit.

\section{INTEGRATION OF PROFESSION-SPECIFIC AND INTERPROFESSIONAL LEARNING}

Some students felt that they had already acquired interprofessional knowledge or skills prior to their DHMP participation, or that other learning experiences provided more depth of learning or a more efficient means of achieving the intended interprofessional objective. A perspective shared by some students was that the DHMP felt "tacked-on," with little reference or linkage to the DHMP detected in their home program learning experiences. Despite positive attitudes toward the aims of the program and their interaction with the mentors, some students perceived little integration between the DHMP and their home programs in terms of relevancy to their program-specific professional role or in enhancing profession-specific learning. The mentor's fit with the professions represented on the team was a factor in per- 
14

Interprofessional Education Program

Doucet, MacKenzie, Loney, GoddenWebster, Lauckner, Brown, Andrews, \& Packer
Journal of Research in Interprofessional Practice and Education

Vol. 4.2 November 2014 ceived relevancy to their program curricula. Students reported unsatisfying experiences when they perceived that their profession was not directly applicable to the mentor's situation or condition. The qualitative data also suggested that the experience was perceived as more relevant to students in practice-based programs.

\section{SCHEDULING CONFLICTS}

While 11 of 16 participating programs had the same protected IPE time, the lack of protected time among all participating programs appeared to contribute to students' perceptions that the IPE experience was an inefficient learning experience that involved significant time costs, chiefly because of the scheduling and co-ordination problems they experienced. When time was not allotted for DHMP activities within their professional programs, students often experienced conflicts between the DHMP teamwork or supervisory meetings with other highly prioritized profession-specific learning activities. Adding to students' frustration was the aforementioned lack of perceived benefit from the DHMP activities and co-ordination and scheduling difficulties that affected their personal or work time. Other students found their clinical commitments overrode their DHMP participation, pressuring teams to accommodate their schedules in off-hours. Even though the majority of programs did allot time for DHMP activities, their students' protected time was rendered ineffective without universal implementation across programs. As a result, teams were forced to meet outside of school hours, in evenings, and on weekends to accommodate students without allotted time. The time and attention required to address scheduling problems detracted from the learning experience, as this student's comment indicated: "With different programs having very different schedules, this program became more of an exercise in scheduling than in learning about chronic conditions and interprofessional collaboration." An unanticipated effect of allotting time within only some programs for IPE events created frustration for all. There was also a perception that time diverted to the DHMP could be better spent on other professional content. One student termed this a "sacrifice" when comparing their program with others lacking DHMP protected time.

\section{ACADEMIC CREDIT}

A perceived lack of academic credit for the time and effort required was explicit in the qualitative comments from students in four programs; the extent to which others agreed with this perspective is unknown. As a motivational factor, academic credit was clearly important, as expressed by this student:

I thought all the exercises and assignments we did were pointless. I didn't learn anything from them. We didn't get a grade for this, so I found it hard to care about it, especially since I didn't need the credit to graduate.

Similarly, this student's comments indicate that the lack of academic credit did not reconcile with their workload, adversely affecting attitudes toward the program and its potential value: 
Interprofessional Education Program

Doucet, MacKenzie, Loney, GoddenWebster, Lauckner, Brown, Andrews, \& Packer

Journal of Research in Interprofessional Practice and Education

Vol. 4.2 November 2014

\section{Journal of Research in Interprofessional Practice and Education}

The last thing we have on our minds is a class that is simply PASS/FAIL and has no effect on our GPAs, as there are sciencebased classes that we are taking that have much more of an impact on our professional lives. If the health mentor program wasn't so assignment based, I think it would have been much more welcome by ... students.

Beyond some students' desire to receive credit for the work they have done in the DHMP, this quote also alludes to the perceived relative importance of "sciencebased" course work, which some students assessed as more directly relevant to their professional development than the DHMP. This suggests that the perceived value of the learning experience may be tied to the academic credit assigned and/or that a disconnect between the perceived value of academic assignments and the number of assignments (ten in total) can be a barrier to student learning. Students detected a misplaced emphasis on producing work for evaluation purposes to the detriment of the overall learning experience.

\section{Team composition}

Contextually, the goal was for students to learn about the mentor as a person first, rather than focusing on the contribution/role of each student's particular profession to their care. Participation in the DHMP prior to learning profession-specific values, roles, and culture was expected to encourage a focus on team collaboration. Despite the positive intention of creating a patient-centred focus, team composition factors led to unintended barriers to some students' learning. Three factors pertaining to team composition were highlighted by students: level of learner, professional relevance of team members, and mentor-team mismatch.

LEARNER LEVEL

The timing of the DHMP experience in the professional program varied across programs (from first to third year in an undergraduate program, to graduate students in professional programs), with most learners in the first year of their professional training. Many students in several programs noted that first year was too early for this type of interprofessional experience. First year students perceived they were unable either to contribute fully or to knowledgably represent their profession; this reduced mutual learning among the team members. However, from the perspective of students further along in their programs, a mix of experienced and less-experienced students was also unsatisfying. Comments from third-year students indicated that this was not an appropriate time for their participation in the DHMP, and they favoured an earlier program experience. They felt they had already acquired much of the knowledge and skills offered through the DHMP, thus reducing the program's relevancy. While they shared their knowledge with less-experienced team members, those teammates could not mutually reciprocate or advance the experienced students' knowledge. The qualitative data suggested that disparate levels of university experience and maturity within the team could be a limitation to full participation. 
16

Interprofessional Education Program

Doucet, MacKenzie, Loney, GoddenWebster, Lauckner, Brown, Andrews, \& Packer
Journal of Research in Interprofessional Practice and Education

Vol. 4.2 November 2014
The more-experienced university students (regardless of year in their professional program) took on time-consuming team leadership and coordination activities by default, which they sometimes perceived as unfair. The timing of the DHMP in the individual professional programs influenced the levels of experience within the teams. Participants thought this sometimes negatively affected the quality of discussion during team meetings with the faculty supervisors since inexperienced or lessknowledgeable members could not contribute fully.

\section{PROFESSIONAL RELEVANCY}

A second factor pertaining to team composition was that the relevance of the experience was diminished when teams contained professions that had low probability of interacting in actual practice settings. Students felt that they did not increase their understanding of how to work with professions they would likely encounter in collaborative care when they were not matched accordingly. This also contributed to the perception that the interprofessional component was a poor educational simulation in some students' experiences.

\section{MENTOR-TEAM MISMATCHES}

Students had difficulty with the applicability of the experience when the student's specialty was not realistically involved in addressing their mentor's chronic condition or disability. They were left to search for theoretical examples of how they might work with others as opposed to learning from their mentor's authentic experiences in the healthcare system.

\section{Interprofessional learning activities}

The written responses suggested that the learning activities represented a poor simulation of interprofessional collaboration students might realistically expect to encounter in practice. As one student remarked, "simply working on a timeline [of the mentor's life] with nurses, respiratory therapists, et cetera, does not help me understand our individual roles in, say, a hospital setting." Whether or not the overall team experience per se was positive or negative did not appear to be an explanatory factor in students' perceptions that there was no useful interprofessional experience. For instance, many commented on a positive teamwork experience while simultaneously noting the interprofessional collaborative experience was absent. Students described that the opportunity to interact within their professional roles was limited, and there was both a lack of focus and an under-exploration of the interprofessional aspect at the student team and supervisor team meetings (related to this were team composition factors that also posed barriers, which were discussed above). Students felt that they were not permitted to exert their professional role in their interactions with the mentor because, as previously noted, students were explicitly instructed not to provide intervention or advice. Mentor interactions were focused on gathering information from and reflecting back to the mentor his or her own story; students therefore reported that the opportunity to explore professional contributions in collaborative relationships was limited. 
17

Interprofessional Education Program

Doucet, MacKenzie, Loney, GoddenWebster, Lauckner, Brown, Andrews, \& Packer
Journal of Research in Interprofessional Practice and Education

Vol. 4.2 November 2014
Even though the experience of talking to a health mentor appeared to have perceived value and the health mentor story assignment was the most positively rated, the assignment received mixed reviews qualitatively. Some students reported that reflecting back to the mentor their own story resulted in little, if any, additional skill development. Some students felt that they could have accomplished the same outcomes working with colleagues in their own programs. While there were several highly positive comments about the mentor relationship and interaction, some students reported their particular mentor was not responsive or clear about the mentor role or the DHMP goals.

Team meetings with the supervisor were planned as a vehicle for interprofessional learning but were viewed as unproductive, despite congenial and positive supervisors. These meetings were tainted by scheduling conflicts and lack of participation from inexperienced students who may have lacked enough knowledge about the mentor's condition or their own profession to contribute fully.

Students also perceived there was excessive reporting about team functioning, which they criticized as an "unnecessary," "time-wasting," or "redundant" exercise for well-functioning teams. As one student remarked, reflections and reports were only "completed because they had to be done." The suggestion was made that these instruments might possibly be helpful when problems existed, but even so, students also described how the team functioning reports, often completed as a group, were problematic because they lacked anonymity and thus were not accurate portrayals of team functioning when there were difficulties. They were perceived as an irritant that contributed to the negative viewpoint that the program's assignments overall were ineffective. As summarized by one student: "The exercises were not useful. They were merely one more hoop to jump through before we could put this course behind us, and did not serve to deepen learning at all." Furthermore, some students viewed these assignments as incongruent with adult learning principles because they were not practical or relevant, adding to their dissatisfaction. Peer assessments were not seen as useful or efficient either, especially when there were no problems. Some students found the third mentor visit redundant, of little perceived added value and thus an inefficient use of time.

\section{Students' recommendations and suggestions for improvement}

Over $80 \%(N=165)$ of those providing free text comments offered recommendations and suggestions for program improvement. Ten percent of the students who made recommendations held extreme positions, suggesting making no changes, making the program voluntary or exempting experienced students, or eliminating the entire DHMP program for their program's participation. Consistent with the fact that most students felt the course objectives were met, the vast majority of comments centred on program design or implementation changes that would alleviate the unintended learning barriers they experienced. There were three main categories of recommendations for program improvement: 1) integration of the DHMP into home programs, 2) interaction with the mentors, and 3) interprofessional learning experiences. Table 7 displays the recommendations for improvement and the learning bar- 


\section{JRIPE}

18

Interprofessional Education Program

Doucet, MacKenzie, Loney, GoddenWebster, Lauckner, Brown, Andrews, \& Packer
Journal of Research in Interprofessional Practice and Education

Vol. 4.2

November 2014 riers they potentially address. As noted in the table, several recommendations have the potential to impact more than one of the unintended but identified student learning barriers.

Table 7

\section{Students' recommendations and the barriers to learning they potentially address}

\begin{tabular}{|c|c|c|c|}
\hline \multirow{2}{*}{ Recommendation } & \multicolumn{3}{|c|}{$\begin{array}{l}\text { Barriers to learning: Unintended DHMP } \\
\text { curriculum influences }\end{array}$} \\
\hline & $\begin{array}{l}\text { Curriculum } \\
\text { integration }\end{array}$ & $\begin{array}{c}\text { Team } \\
\text { composition }\end{array}$ & $\begin{array}{l}\text { IPE learning } \\
\text { activities }\end{array}$ \\
\hline \multicolumn{4}{|l|}{1.0 Improve integration of the DHMP } \\
\hline 1.1 Allot common meeting times & $x$ & & $x$ \\
\hline $\begin{array}{l}\text { 1.2 Consider exam and break schedules in planning } \\
\text { HMP activity }\end{array}$ & $x$ & & $x$ \\
\hline 1.3 Provide academic credit & $x$ & & \\
\hline $\begin{array}{l}\text { 1.4 Reduce workload \& time commitment: Keep it } \\
\text { simple \& short }\end{array}$ & $x$ & & $x$ \\
\hline \multicolumn{4}{|l|}{2.0 Improve interaction with health mentors } \\
\hline 2.1 Improve interaction in mentor meetings & & & $\mathrm{x}$ \\
\hline $\begin{array}{l}\text { 2.2 Match mentors to teams composed of professionals } \\
\text { relevant to the mentors' condition(s) or disability }\end{array}$ & & $x$ & $x$ \\
\hline 2.3 Ensure mentor suitability for the program & & $x$ & $x$ \\
\hline \multicolumn{4}{|l|}{ 3.0 Improve the interprofessional experience } \\
\hline 3.1 Change timing in the professional program. & $x$ & $x$ & $x$ \\
\hline $\begin{array}{l}\text { 3.2 Improve team composition to increase professional } \\
\text { relevancy }\end{array}$ & & $x$ & $x$ \\
\hline $\begin{array}{l}\text { 3.3 Improve clarity around DHMP goals and align } \\
\text { learning activities with objectives }\end{array}$ & $x$ & & $x$ \\
\hline
\end{tabular}

Improve integration of the DHMP

Students offered two recommendations concerning the pervasive and frustrating scheduling problems. The third and fourth recommendations addressed the lack of academic credit and the program workload and time commitment.

\section{AlLOT COMMON MEETING TIMES}

When the DHMP was not integrated fully within the student's program, students were confronted with missing either the DHMP activity (and inconveniencing their team) or missing learning experiences in their home program (which were highly valued and also worth more academic credit). In the students' eyes, curriculum integration, including allocating devoted time for all team members, was the key remedy to 
Interprofessional Education Program

Doucet, MacKenzie, Loney, GoddenWebster, Lauckner, Brown, Andrews, \& Packer
Journal of Research in Interprofessional Practice and Education

Vol. 4.2 November 2014

\section{Journal of Research in Interprofessional Practice and Education}

alleviate time-consuming scheduling problems. For instance, many students (including students from programs who had protected IPE time) asked that professional programs allot common meeting times, as one student explained:

I believe that each professional should have a specific time dedicated to health mentor activities. All the professions were not able to make the meeting times with health mentors, as our schedules were so noncohesive. It was very difficult finding a time that worked for all of us.

Another student elaborated:

I'm wondering if there is a way to better integrate the schedules of the programs so that more can be done during daytime hours. All of our team meetings took place in the evenings. It was enormously difficult to find times that worked for all team members and our health mentor. One of our team members had to pay for childcare so she could attend some of our team meetings. We all have very busy schedules and obligations at home. I think it's worth exploring how this program could be better integrated into each profession's curriculum.

Students suggested scheduling mentor meetings within allotted common times in all programs' schedules. Some students viewed the mentor meeting times as a program responsibility. It was suggested times could either be established before the academic year or provided for in DHMP allotted time slots.

\section{CONSIDER EXAM AND BREAK SCHEDULES IN PLANNING DHMP ACTIVITY}

Students also requested that consideration be given to university exam schedules and breaks when planning DHMP meetings and deadlines. Students found the DHMP work in the last week of classes was problematic, as exams were often scheduled during that period. Students noted that it was unrealistic to expect teams to conduct preparation during the winter break for a mentor meeting due immediately after the break.

\section{PROVIDE ACADEMIC CREDIT}

The lack of academic credit was un-motivational when students considered the time and effort necessary to complete the program was over and above their regular, credited course work. It was also a source of internal conflict when students were forced to choose between home program activities worth more credit than the DHMP team activity. Some students felt that the program should have more grade weight allocated for their participation in the program. This recommendation was succinctly stated by one student: "This program should be worth more marks-wise due to the large time commitment." This advice came from another student: "Ensure [that] the program is embedded in a course and credit is received."

\section{REDUCE THE WORKLOAD AND TIME COMMITMENT: KEEP IT SIMPLE AND SHORT}

The recommendation to reduce the workload and time commitment for the DHMP was widely and clearly expressed by many students in 11 of the 16 participating pro- 
Interprofessional Education Program

Doucet, MacKenzie, Loney, GoddenWebster, Lauckner, Brown, Andrews, \& Packer
Journal of Research in Interprofessional Practice and Education

Vol. 4.2 November 2014

\section{Journal of Research in Interprofessional Practice and Education}

grams. Comments included the perspective that reducing the workload could shift the focus from completing redundant and seemingly pointless activities or assignments to more focus on authentic learning. The comments below illustrate the students' perspectives, echoing the desire for more effective and efficient use of their time spent on the program.

Too much focus on assignments, team reflection, et cetera. The focus should be on the interaction with the patient. The assignments, orientation meetings, issues with [the online learning system], meetings, et cetera, take a lot of time, and students become disinterested and perhaps start to see the program as too much stuff in comparison to what they get out of it. They will then even start to resent the really important part of the program (mentor meeting). A lot of it is really over kill. Often less is more.

Less paperwork. Keep it simple and emphasize the human interaction more than all those ridiculous forms!

I believe the program would be more effective if it was compressed into one semester. Having the three visits spread out over a year made continuity more difficult because all healthcare programs are very busy and this program fell behind other work.

\section{Improve interaction with health mentor}

Student interactions with their health mentor and exposure to their mentor's perspective are key features of the DHMP, and students offered recommendations in three areas aimed at improving their interaction with the mentor.

\section{IMPROVE INTERACTION IN MENTOR MEETINGS}

Many students expressed the view that they genuinely enjoyed the contact with their health mentor and were appreciative of the mentor's volunteer participation. Nonetheless, a strong recommendation categorized above under "reducing workload" was made by students across several programs to reduce the number of mentor meetings from three meetings to two. In the students' eyes, this recommendation would reduce workload by eliminating an unnecessary visit, but also improve effectiveness. Students did not find much new information or purpose to the second visit, making them feel forced, repetitive, or redundant. A third visit might be made optional if required to complete the assignment, as not all mentors were as forthcoming with information as students might have liked. Some students were looking for more interactive exchanges with the mentors, reporting that it felt unnatural simply listening and drawing out the story, and it could feel awkward presenting the story. Students were mindful that professional input was inappropriate for most given their level of training and the intent of the program. The potential for greater learning was seen if the program moved away from a passive student role in a didactic situation with "mentors telling and students listening" toward a two-way interaction and 
Interprofessional Education Program

Doucet, MacKenzie, Loney, GoddenWebster, Lauckner, Brown, Andrews, \& Packer
Journal of Research in Interprofessional Practice and Education

Vol. 4.2 November 2014

\section{Journal of Research in Interprofessional Practice and Education}

exchange of ideas with the mentors. Suggestions included a different format, such as discussion meetings with mentors and encouraging mentors to interact more. For example, one student explained:

[Our mentor] talked at us the whole time. [It] would be more effective to engage us [as] active participants, i.e., come up with discussion questions (reflective of our experience in our programs), share insight from our experience thus far with the mentor, share something of ourselves with [the] mentor.

MATCH MENTORS TO TEAMS COMPOSED OF PROFESSIONALS RELEVANT TO THE MENTORS' CONDITION(S) OR DISABILITY

Matching teams relevant to their mentors' condition(s) or disability was very important to students in specialized programs, as expressed by this student:

While I understand that group/client selection is random, it would be much more beneficial if students in our program ... could be matched up with someone who either had [discipline-specific] difficulties or if they could potentially have these difficulties in the future based on the course of their illness.

There was also a suggestion to broaden students' exposure to different mentors through alternative activities, such as a panel of mentors meeting with students that would permit an exchange of experiences and ideas.

\section{ENSURE MENTOR SUITABILITY FOR THE PROGRAM}

The successful completion of the program hinged not only on student effort but also on the mentors' responsiveness, health and healthcare history, co-operation, and contributions. Most students providing comments on mentors made positive comments about their mentors. Other students described negative experiences and recommended mentors be more carefully screened. They wanted to ensure mentors are able to communicate and tell their story, are responsive, understand the goals and boundaries, and that mentors have enough contact with the healthcare system to draw on so that their experiences provide useful student learning. Another factor to be considered in mentor screening was the amount of travel time involved in meeting with the mentor. Students described significant additional time costs associated with travel to mentor meetings, especially when they did not have a vehicle.

\section{Improve the interprofessional learning experience}

A major focus of student recommendations was improving the interprofessional learning experience. Key subthemes were 1) changing the timing in the professional program, 2) composing teams with members homogeneous in year/level of professional training and with members most likely to work together in the future, relevant to the mentors' condition or disability; and 3) clarifying the DHMP focus and providing activities that directly address the interprofessional objectives. 
22

Interprofessional Education Program

Doucet, MacKenzie, Loney, GoddenWebster, Lauckner, Brown, Andrews, \& Packer
Journal of Research in Interprofessional Practice and Education

Vol. 4.2

November 2014

\section{CHANGE TIMING IN THE PROFESSIONAL PROGRAM}

Contrasting preferences for early and late timing within professional programs were evident. First-year students expressed that experiencing the DHMP after first year would be preferable, as they expected that they would have more profession-specific knowledge and experience to contribute, thus facilitating a greater depth of mutual learning about their respective contributions to interprofessional collaborative care. One student's comments typified this view: "Develop an interprofessional health team program later on in our education, once people have an idea of what their roles are on a team to simulate what actually working on a collaborative healthcare team is." A firstyear student noted their lack of knowledge, limiting their contribution to the team and their own learning: "The HMP should be in a later year in my program rather than first year. This way we will have more knowledge of ... and we can make better comments or ask better questions." Conversely, third-year students deemed the program more suitable to first year when they had not already acquired the skills required to complete the assignments, and when their professional program had fewer demands. Consistency of program year among team members was another recommendation to prevent tensions introduced when learners had less or more professional education than other team members. In the words of one student: "I feel by having third-year ... students and (for example) first-year ... students, it really made the [third-year] students feel that their role is not as important, and played into the stereotypes of society."

\section{IMPROVE TEAM COMPOSITION}

In order to address the issue of professional relevancy, students suggested comprising teams with students who would plausibly interact in the process of collaborative care and matching that student team with a mentor with conditions or disabilities relevant to the professional mix on the team. A student's comment demonstrates the negative impact on learning when professional relevance was not present: "It would be nice if the mentor has received care from all professions that are assigned to them. I feel [that some] students were able to get more from the program because the mentor had direct experience with these professions."

IMPROVE CLARITY AROUND DHMP GOALS AND ALIGN LEARNING ACTIVITIES WITH OBJECTIVES Some students called for increased clarification of the DHMP program objectives. Within this perspective, some students felt that the learning activities did not explicitly address both the chronic disease and the interprofessional objectives and failed to produce an authentic, efficient, and effective interprofessional learning experience. A student commented that

the program encouraged us to focus on our health mentors as people rather than patients, so we seldom discussed their condition from a medical perspective, nor what our roles would be if caring for him as a patient. It seems like these two goals are in conflict. 
Interprofessional Education Program

Doucet, MacKenzie, Loney, GoddenWebster, Lauckner, Brown, Andrews, \& Packer
Journal of Research in Interprofessional Practice and Education

Vol. 4.2 November 2014

\section{Journal of Research in Interprofessional Practice and Education}

Likewise, another student noted that

some members focused on what they learned about our health mentor as a person, therefore speaking more to our health mentor's personality like resilience. I thought the goal was to learn what we could do as health professionals to improve patient care based on our health mentor's experiences. Objectives should be clarified so everyone is on the same page.

While important messages were received about viewing the patient as a person, students expected all perceived learning goals to be met and accordingly recommended a more explicit focus on interprofessional collaboration and opportunities to explore one's own role and better understand others' roles. Student comments indicated relevancy must be inherent in learning activities to align them with the objectives. One student directly expressed: "I feel like there should be tasks that specifically require people to use skills relevant to their profession." For many students, the assignments called for generic teamwork that lacked a distinct interprofessional element. One student remarked:

I felt it should be more oriented toward actual interprofessionalism. I felt as though we were meeting as four individuals and not contributing based on our professions-just as people. There was no actual program-specific professional input required, which I thought was the original purpose of the program.

Students understood their level of knowledge precluded advising the patient; nonetheless, they wanted ways to directly explore profession-specific input, suggesting alternative activities. These included case studies, shadowing or interacting with actual interprofessional teams, and learning experiences modelled on other interprofessional activities they were engaged in that they perceived were more effective. Students also suggested replacing the program with single-day interprofessional event(s) that would incorporate a variety of mentors, thus increasing the breadth of mentor stories students could learn from.

\section{Discussion}

The overall aim of this analysis, using program evaluation data, was to explore students' learning experiences as participants in the DHMP and to share their perspectives on curricular barriers to learning as students in an IPE program. The exploration of student ratings and textual data in this report provide a more complete understanding of the students' experience than one method alone. For example, over half of the respondents quantitatively agreed that they met the four DHMP learning objectives, that the DHMP learning experience was in the appropriate year of their program, that it made sense for their program to participate, and that they now know more about the professions of other students on their team. However, the qualitative comments describe instructive messages about the barriers to learning the students experienced. Powerful educational experiences can lead a learner to re- 
24

Interprofessional Education Program

Doucet, MacKenzie, Loney, GoddenWebster, Lauckner, Brown, Andrews, \& Packer
Journal of Research in Interprofessional Practice and Education

Vol. 4.2 November 2014 think their values and plans as a health professional [30], so it is important to attend to the perceptions and experiences of the negative experiences that affect learning.

Reflection on the evaluation results provides insight into broader issues that may be causing such programs to be received differently than intended. The quantitative and qualitative findings illuminated three areas for improvement from the student perspective, providing a basis for data-driven program improvement. Specifically, the recommendations proposed by students provide ways to improve three main program components: 1) integration of the DHMP into home programs, 2) interaction with the mentors, and 3) interprofessional learning experiences.

Building upon the students' recommendation specific to this health mentor IPE learning opportunity, we also identify three key lessons learned that may be applied to other related IPE initiatives:

\section{Managing student learning expectations in light of sequential IPE skill} development is a delicate balance and requires explicit attention.

The current evaluation increases our understanding that despite the significant learning that occurred with respect to seeing the patient/client as a person first and the majority of students reporting that the DHMP objectives were met, some students were still hoping to learn more about interprofessional roles. For these students the under-emphasis on this specific interprofessional objective was a lost opportunity. Learning about interprofessional roles was not one of the objectives of the DHMP; therefore, students felt that they were left to vicariously or indirectly learn about their interprofessional role through their mentor's eyes, which students felt was not the most effective way to learn basic interprofessional concepts. Not surprisingly, the students most dissatisfied with learning about others' roles were more apt to provide textual comments. The students had expected to develop role clarification as a foundational competency, but in the students' eyes this expectation was not met through the DHMP learning activities. Students appeared to equate role clarification with interprofessional education, even though role clarification was not an intended objective of the DHMP. As indicated earlier, the three CIHC competencies focused on in the DHMP were interprofessional communication, team functioning, and patient/client-centred care. Perhaps it is not possible for students to meet these competencies without first understanding the professional roles and responsibilities of each team member. In particular, it may be difficult for students to communicate as an interprofessional team in a collaborative, responsive, and responsible manner [20] when they may not be aware of the unique professional perspective of each team member.

The student concerns about team composition, professional relevancy, and mentor fit also reflect the differences between the DHMP as intended and the resultant student perceptions, experiences, and expectations as reported in this paper. The program evaluation data suggests students had the expectation that they would achieve the goal of interprofessional collaboration to ensure patients/clients have "access to the right professional at the right time in the right place" [31, p. 1], despite this not being one of the planned objectives. Data also indicate that for many students this expectation was clearly not met in the DHMP learning experience. There was no 
25

Interprofessional Education Program

Doucet, MacKenzie, Loney, GoddenWebster, Lauckner, Brown, Andrews, \& Packer

Journal of Research in Interprofessional Practice and Education

Vol. 4.2 November 2014 matching of student teams or mentors, other than to ensure that there was diversity in the professional representation. Students commented that while they could function well as a team completing an assignment, they did not have opportunities to explore professional roles within the structure of their assignments and team supervisor meetings; the "interprofessional" element did not develop as they expected. The unintended message that was inadvertently communicated was that IPE does not have to represent real-world teams and therefore may not be relevant to real-world practice. The students detected this mismatch, and it could be argued that it demonstrates that they value interprofessional work even though their IPE experience may have fallen short of their expectations. While it seems it would be preferable to have a more systematic fit between the mentor and the team composition, issues of logistics to administer the DHMP prevailed, which is a common limitation in IPE program planning [32].

Complicating the team composition issue was the fact that not all participating students were in their first year of study, and that students in some programs were at a different level of personal maturity than others. As well, a number of students in these programs brought past experience in other health professions. In arguing for the need for theory in developing IPE activities, Hean, Craddock, and O'Halloran [33] discussed the need to consider "stage development" in knowledge acquisition and that the "interaction between existing and new knowledge is important in learning and has led to the recognition that teaching must take account of students' existing knowledge" [p. 255]. In our earlier research with a different DHMP cohort [6], the health mentors recommended that students have the opportunity to develop basic interviewing skills before participating in the DHMP, as many of the mentors felt that the students were not prepared to ask open-ended or follow-up questions. The health mentors wanted the students to take a more active role in asking questions and move beyond just taking notes. Interestingly, this is consistent with the students' recommendation for the DHMP to move away from a passive student role in a didactic situation with "mentors telling and students listening" toward a two-way interaction and exchange of ideas with the mentors. However, students, particularly those in the first year of their training, likely lacked the foundational interviewing skills to take on this active role.

The original intent of the DHMP was to introduce students to the concepts of IPE, particularly patient/client-centred care, in the first year of their professional programs. The hope was that matching the first-year students at a similar stage in their professional intellectual development within their program might ensure the success of IPE [34]. However, programs are given the autonomy to decide on the appropriate placement of the program within their respective curricula. Perhaps the goal that the DHMP is an introduction to IPE needs to be made far more explicit to the programs and students. Additionally, DHMP as an introductory IPE experience needs to be put into the broader context of other IPE activities that the students will experience later in their programs. Finally, for students to gain the maximum benefit from such programs, it is critical to ensure that all students have the necessary basic communication skills to ensure active participation. 
Interprofessional Education Program

Doucet, MacKenzie, Loney, GoddenWebster, Lauckner, Brown, Andrews, \& Packer
Journal of Research in Interprofessional Practice and Education

Vol. 4.2 November 2014
2. To be valued by students, IPE initiatives must be integrated and valued (e.g., given credit) within their own programs.

Student perceptions regarding the value of IPE were related to how well DHMP was integrated into their respective program's curriculum, assignment of credit for the work completed, and scheduling challenges. Within the 16 programs that participated in the DHMP, there was considerable variation among how the DHMP was integrated into the respective curricula. The curricular integration differences were also reflected to some extent in how academic credit was assigned to students participating in the DHMP. While some programs embedded the DHMP within a program course as described elsewhere [35], many other programs had participation in the DHMP as a stand-alone learning experience. Additionally, some students devalued the experience because they did not receive a specific grade (apart from pass/fail) or that they perceived the program was not meeting their "science-based" educational needs. Finally, students voiced concern that even if their respective program had a common time assigned for IPE, if the other members on the team did not have the same common time, the message received was that the encounter was either not valued, or it was preventing other learning perceived as more valuable. While experiencing and working through the challenges of finding common meeting times might serve to highlight the importance of co-ordinated care, not all students found this process a valuable learning experience. Depending on the practices of their particular program, the unintended message may be that although the home program requires student participation in the DHMP, such participation is not really valued in comparison to the profession-specific curriculum. These perspectives underscore the potential need to integrate the DHMP fully across programs and within programs and existing courses-where integration can be explicitly communicated to students.

\section{Sometimes well-intended assignments do not elicit the intended IPE learning; Learning activities must inherently elicit an opportunity to learn.}

The third lesson learned relates to the number and nature of the assignments. The assignments with the mentors were intended to focus the students on the mentor as a person and the mentor's experience with a chronic condition. They were also designed to reflect the learner level and the kinds of activities that the students might reasonably engage in unsupervised with the mentors. However, the students did not see the assignments as reflecting issues of IPE because, as noted earlier, they did not address issues of role clarification. In addition, the assignments were seen by some students as lacking relevance to their profession and may have unintentionally suggested that interprofessional education and collaboration deal with soft issues of marginal significance. Assignments that explicitly require input from different health professions might be more valued. For example, in the original Jefferson University Health Mentors Program [19], the mentor story was only the first of four modules. The subsequent modules seemed to require more interprofessional input from team members who were from fewer and more closely related professional programs than the team members in the DHMP. 
27

Interprofessional Education Program

Doucet, MacKenzie, Loney, GoddenWebster, Lauckner, Brown, Andrews, \& Packer
Journal of Research in Interprofessional Practice and Education

Vol. 4.2 November 2014
Although the inclusion of so many programs in the DHMP may have contributed to concerns about team composition, this was purposefully implemented to expose learners from a wide variety of professions to concepts of patient/client-centred care, interprofessional collaboration, and the diversity and complexity of the healthcare system.

Finally, team functioning reports were designed to have the students focus on issues of interprofessional collaboration; however, these assignments were seen by many to be contrived, lacking relevance, producing inaccurate portrayals of team function, and time wasting. These perceptions may reflect an unintended message that reflecting and talking about team functioning with one's team members can be awkward and uncomfortable. Perhaps these student teams are too short-lived, or too diverse, and not sufficiently cohesive to enable this sort of discussion.

In summary, this program evaluation has indicated a number of areas in which changes can and should be made to the DHMP to facilitate the achievement of its goals and to ensure that the unintended messages or learning experiences do not undermine these goals. As well, the issues that emerged from this analysis point to the need for students to be better acquainted with where the DHMP fits into the broader IPE curriculum of their particular program. Most programs within the DHMP require the students to have completed a number of IPE activities by the time they graduate, including activities in the practice setting [36]. Students need to understand that the DHMP is intended to be an introduction to IPE and does not constitute the entirety of their IPE experiences-learning about students in other health professions is the first step in their journey to become collaborative practitioners. What the students can expect from the DHMP is an understanding that people with chronic conditions should be viewed as members of a team comprised of many different health professionals. They also can expect to come to understand and appreciate the patient as a whole person with a life that extends beyond their chronic condition. The new learning from this program evaluation study is relevant to individuals who are involved in planning health mentors programs or other related longitudinal IPE programs.

\section{Limitations}

There are several limitations to this analysis. These are findings from a program evaluation rather than a controlled research protocol. Questions were deliberately framed to elicit information to help improve the program, rather than to elicit a complete picture of the students' learning and experience. The online survey focused on process outcomes; standardized research tools to measure student outcomes were not included. Completion was voluntary and students knew that the survey would be used to improve program content and delivery. Although those who provided comments appeared to be similar to those who did not, it is possible that students who had less positive viewpoints chose to respond. We unfortunately did not have access to the demographics of age, total university experience, previous healthcare experience, nor the percentage of respondents who were from the same team, and whether their collective perception of the learning experience was positive or nega- 
JRIPE

28

Interprofessional Education Program

Doucet, MacKenzie, Loney, GoddenWebster, Lauckner, Brown, Andrews, \& Packer
Journal of Research in Interprofessional Practice and Education

Vol. 4.2 November 2014

\section{Journal of Research in Interprofessional Practice and Education}

tive. We are also unable to comment about the persistence of the negatively rated items from this experience in terms of how they will affect the students' future prelicensure or post-licensure interprofessional experiences.

\section{Conclusion}

The program evaluation information addressed within this article and our lessons learned are instructive not only to program planners for the DHMP, but for those who plan any IPE experience. Educators need to be aware of the students' experiences with the intended and unintended curricular factors that will always be present and influential in student learning. The goal of this article is to share our experience and highlight the need for IPE program planners to be aware of not just the positive outcomes, but also to expect and watch for unintended or unplanned learning experiences and how these may adversely affect the good intentions of IPE initiatives. The results of this evaluation informed several changes to the 2013-2014 DHMP.

\section{Acknowledgements}

We would like to acknowledge all stakeholders who have been involved in the development and implementation of the DHMP. In particular, we wish to acknowledge the generosity and good will of the health mentors in sharing their experiences with our students. We would also like to thank the 2013-2014 DHMP Director and Manager for their helpful review of this paper and to acknowledge the contributions of the 2012-2013 DHMP Coordinator, particularly in the development and implementation of the program evaluation questionnaire. Finally, we would also like to thank Horizon Health Network for funding this research through the Health Innovation and Research Fund.

\section{Abbreviations \\ CIHC Canadian Interprofessional Health Collaborative \\ DHMP Dalhousie Health Mentors Program}

\section{References}

1. Barr, V.J., Robinson, S., Marin-Link, B., Underhill, L., Dotts, A., Ravensdale, D. \& Salivaras, S. (2003). The expanded Chronic Care Model: An integration of concepts and strategies from population health promotion and the Chronic Care Model. Hospital Quarterly, 7, 73-82.

2. Greenhalgh, T. (2009). Patient and public involvement in chronic illness: Beyond the expert patient. British Medical Journal, 338, b49.

3. Hibbard, J.H., Collins, P.A., Mahoney, E., \& Baker, L.H. (2010). The development and testing of a measure assessing clinician beliefs about patient self-management. Health Expectations, 13, 65-72.

4. Hibbard, J.H., Stockard, J., Mahoney, E.R., \& Tusler, M. (2004). Development of the Patient Activation Measure (PAM): Conceptualizing and measuring activation in patients and consumers. Health Services Resarch, 39, 1005-1026.

5. Towle, A., Bainbridge, L., Godolphin, W., Katz, A., Kline, C., Lown, B., Madularu, I., Solomon, P., \& Thistlethwaite, J. (2010). Active patient involvement in the education of health professionals. Medical Education, 44, 64-74.

6. Doucet, S., Laukner, H., \& Wells, S. (2013). Patients' messages as health educators in an interprofessional health education program. Journal of Research in Interprofessional Practice and Education, 3, 92-102. 
29

Interprofessional Education Program

Doucet, MacKenzie, Loney, GoddenWebster, Lauckner, Brown, Andrews, \& Packer
Journal of Research in Interprofessional Practice and Education

Vol. 4.2 November 2014
7. Orchard, C.A. (2010). Persistent isolationist or collaborator? The nurse's role in interprofessional collaborative practice. Journal of Nursing Management, 18, 248-257.

8. Virani, T. (2012). Interprofessional collaborative teams. Ottawa, ON: Canadian Health Services Research Foundation. URL: http://www.cfhi-fcass.ca/sf-docs/default-source/commissionedresearch-reports/Virani-Interprofessional-EN.pdf?sfvrsn=0 [February 24, 2014].

9. Brennan, C.W., Olds, D.M., Dolansky, M., Estrada, C.A., \& Patrician, P.A. (2014). Learning by doing: Observing an interprofessional process as an interprofessional team. Journal of Interprofessional Care, 28(3), 249-251.

10. Jeffs, L., Abramovich, I.A., Hayes, C., Smith, O., Tregunno, D., Chan, W. H., \& Reeves, S. (2013). Implementing an interprofessional patient safety learning initiative: Insights from participants, project leads and steering committee members. BMJ Quality \& Safety, 22, 923-930.

11. Accreditation of Interprofessional Health Education (AIPHE). (2012). AIPHE interprofessional health education accreditation standards guide-phase 2. URL: http://www.cihc.ca/files /resources/public/English/AIPHE\%20Interprofessional\%20Health\%20Education\%20Accredita tion\%20Standards\%20Guide_EN.pdf [September 13, 2013].

12. World Health Organization. (2010). Framework for action on interprofessional education and collaborative practice. Geneva, Switzerland: WHO. URL: http://whqlibdoc.who.int/hq/2010/WHO _HRH_HPN_10.3_eng.pdf?ua=1 [October 10, 2014].

13. Serembus, J.F., Meloy, F., \& Posmontier, B. (2012). Learning from business: Incorporating the Toyota Production System into nursing curricula. The Nursing Clinics of North America, 47, 503-516.

14. Reeves, S., Goldman, J., \& Oandasan, I. (2007). Key factors in planning and implementing interprofessional education in health care settings. Journal of Allied Health, 36, 231-235.

15. Hafferty, F.W. (1998). Beyond curriculum reform: Confronting medicine's hidden curriculum. Academic Medicine, 73, 403-407.

16. O'Sullivan, H., van Mook, W., Fewtrell, R., \& Wass, V. (2012). Integrating professionalism into the curriculum: AMEE Guide No. 61. Medical Teacher, 34, e64-77.

17. Gofton, W., \& Regehr, G. (2006). What we don't know we are teaching: Unveiling the hidden curriculum. Clinical Orthopaedics and Related Research, 449, 20-27.

18. Doucet, S., Andrews, C., Godden-Webster, A.L., Lauckner, H., \& Nasser, S. (2012). The Dalhousie Health Mentors Program: Introducing students to collaborative patient/client-centered practice. Journal of Interprofessional Care, 26, 336-338.

19. Collins, L., Arenson, C., Jerpbak, C., Kane, P., Dressel, R., \& Antony, R. (2011). Transforming chronic illness care education: A longitudinal interprofessional mentorship curriculum. Journal of Interprofessional Care, 25, 228-230.

20. Canadian Interprofessional Health Collaborative. (2010). A national interprofessional competency framework. URL: http://www.cihc.ca/files/CIHC_IPCompetencies_Feb1210.pdf [November 8, 2013].

21. Braxton, J.M., Milem, J.F., \& Sullivan, A.S. (2000). The influence of active learning on the college student departure process: Toward a revision of Tinto's theory. Journal of Higher Education, 71, 569-590.

22. Popkess, A.M., \& McDaniel, A. (2011). Are nursing students engaged in learning? A secondary analysis of data from the National Survey of Student Engagement. Nursing Education Perspectives, 32, 89-94.

23. Spencer, J.A., \& Jordan, R.K. (1999). Learner centred approaches in medical education. British Medical Journal, 318, 1280-1283.

24. Greer, A.G., Pokorny, M., Clay, M.C., Brown, S., \& Steele, L.L. (2010). Learner-centered characteristics of nurse educators. International Journal of Nursing Education Scholarship, 7, Article 6.

25. Creswell, J.W., Plano Clark, V.L., Gutmann, M.L., \& Hanson, W.E. (2003). Advanced mixed methods research designs. In Tashakkori, A., \& Teddlie, C. (Eds.), Handbook of mixed methods in social \& behavioral research. (pp. 209-240). Thousand Oaks, CA: SAGE Publications.

26. Braun, V., \& Clarke, V. (2006). Using thematic analysis in psychology. Qualitative Research in Psychology, 3, 77-101.

27. Thomas, D.R. (2006). A general inductive approach for analyzing qualitative evaluation data. American Journal of Evaluation, 27, 237-246.

28. Elo, S., \& Kyngas, H. (2008). The qualitative content analysis process. Journal of Advanced Nursing, 62, 107-115.

29. Richards, L. (2005). Handling qualitative data: A practical guide. London: SAGE Publications.

30. Phillips, S.P., \& Clarke, M. (2012). More than an education: The hidden curriculum, professional attitudes and career choice. Medical Education, 46, 887-893. 


\section{JRIPE}

30

Interprofessional

Education Program

Doucet, MacKenzie, Loney, GoddenWebster, Lauckner, Brown, Andrews, \& Packer

\section{Journal of Research in Interprofessional Practice and Education}

31. World Health Professions Alliance. (2013). WHPA Statement on interprofessional collaborative practice. URL: http://www.whpa.org/WHPA_Statement_collaborative_practice.pdf [November 4, 2013].

32. Craddock, D., O’Halloran, C., McPherson, K., Hean, S., \& Hammick, M. (2013). A top-down approach impedes the use of theory? Interprofessional educational leaders' approaches to curriculum development and the use of learning theory. Journal of Interprofessional Care, 27, 65-72.

33. Hean, S., Craddock, D., \& O'Halloran, C. (2009). Learning theories and interprofessional education: A user's guide. Learning in Health \& Social Care, 8, 250-262.

34. Cooper, H., Carlisle, C., Gibbs, T., \& Watkins, C. (2001). Developing an evidence base for interdisciplinary learning: A systematic review. Journal of Advanced Nursing, 35, 228-237.

35. MacKenzie, D., \& Merritt, B.K. (2013). Making space: Integrating meaningful interprofessional experiences into an existing curriculum. Journal of Interprofessional Care, 27, 274-276.

36. Webster, W.G. (2013). Cultivating grassroots IPE: The Dalhousie University experience. Journal of Interprofessional Care, 27, 96-97. 